\title{
HUBUNGAN ANTARA KEPRIBADIAN DENGAN GAYA BELAJAR MAHASISWA
}

\author{
GITA SEKAR PRIHANTI*
}

\begin{abstract}
ABSTRAK
Latar belakang : Kepribadian adalah karakteristik unik seseorang yang mempengarubi perilaku. Gaya belajar merupakan gambaran sikap dan perilaku yang menentukan cara kesukaan seseorang dalam belajar. Setiap individu memiliki gaya belajar masing-masing yang perlu diketahui agar dapat mengoptimalkan proses dan hasil belajarnya. Dengan adanya pengaruh kepribadian terhadap perilaku seseorang, maka dapat diasumsikan babwa kepribadian dapat mempengarubi gaya belajar yang merupakan gambaran sikeap dan perilaku dalam belajar. Sampai saat ini belum terdapat penelitian mengenai bubungan kepribadian dan gaya belajar. Di Fakultas Kedokteran Universitas Muhammadiyah Malang (FK UMM), belum pernah dilakukan identifikasi gaya belajar mahasiswa sehingga mahasiswa FK UMM tidak menyadari gaya belajar yang dimilikinya. Selain itu identifikasi kepribadian mahasiswa belum dilakukan secara rutin. Oleh karena itu penulis tertarik untuk meneliti mengenai hubungan kepribadian dan gaya belajar mahasiswa di FK UMM.
\end{abstract}

Metode: Desain penelitian ini adalah cross sectional dan melibatkan 480 mahasiswa dari seluruh semester di FK UMM sebagai responden. Tes kepribadian menggunakan Edward Personal Preference Schedule (EPPS) sedangkan gaya belajar menggunakan tipe Honey dan Mumford.

Hasil : Dari analisis chi-square didapatkan kepribadian tidak berbubungan dengan gaya belajar mahasiswa (p>0,05). Karakteristik sosiodemografi yang berbubungan secara signifikan $(p<0,05)$ dengan gaya belajar mahasiswa adalah jenis kelamin dan semester. Sedangkan usia dan asal SMU tidak berhubungan dengan gaya belajar $(p>0,05)$

Kesimpulan : Kepribadian, usia dan asal SMU tidak berbubungan dengan gaya belajar sedangkan jenis kelamin dan semester berbubungan dengan gaya belajar mahasiswa.

Kata kunci: Kepribadian, Gaya belajar, sosiodemografi, usia, jenis kelamin, asal SMU, semester

\footnotetext{
* Staff Pengajar Fakultas Kedokteran

Universitas Muhammadiyah Malang
} 


\title{
THE RELATIONSHIP BETWEEN PERSONALITY AND LEARNING STYLE OF STUDENT
}

\author{
GITA SEKAR PRIHANTI
}

\begin{abstract}
Background: Personality is a person's unique characteristics that influence behavior. Learning style is an attitude and behavior that determine a person's favorite way of learning. Every individual has learning styles that need to be understood in order to optimize the learning process and result. According to the influence of the personality of a person's behavior, it can be assumed that personality can affect learning style which is an attitudes and behavior in learning. There has not been study about the relationship of personality and learning style. At the Faculty of Medicine, University of Mubammadiyah Malang (UMM), has never been identifying the learning styles of students so that students do not realize their learning style. Beside that, the identification of a student's personality has not done routinely. Therefore it is necessary to study the relationship of personality and learning styles of medical students at University of Muhammadiyah Malang.
\end{abstract}

Methods: The study design was cross sectional and involved 480 students from throughout the semester in FK UMM as a respondent. Personality tests using Edward Personal Preference Schedule (Epps) while using these types of learning styles Honey and Mumford.

Results: From chi-square analysis, personality is not related to student learning styles ( $>>0.05)$. Sociodemographic characteristics were significantly associated $(p<0.05)$ with the student's learning style is gender and semester. While the origin of bigh school age and not related to learning styles $(p>0.05)$

Conclusion: Personality, age and origin of high school is not related to learning styles while gender and semester related to student learning styles.

Key words: Personality, learning style, sociodemographic, age, gender, origin of high school, semester

\section{PENDAHULUAN}

Gaya belajar adalah gambaran sikap dan perilaku yang menentukan cara kesukaan seseorang dalam belajar (Coffield F, Moseley D, Hall E \& Ecclestone K, 2004).

Dalam belajar, setiap individu memiliki gaya belajar masing-masing. Kesadaran tentang gaya belajar yang dimiliki merupakan hal yang penting untuk dapat mengoptimalkan hasil belajar individu. Hal ini disebabkan gaya belajar dapat mempengaruhi hasil belajar mahasiswa. Pengenalan dan pemahaman mengenai gaya belajar masing-masing akan membantu mahasiswa mengoptimalkan belajar mereka secara efektif dan efisien (Curry L, 2002). Bagi pengajar, dengan mengetahui gaya belajar mahasiswa maka pengajar dapat merencanakan strategi pengajaran yang dapat mengakomodir gaya belajar mahasiswa sehingga meningkatkan pemahaman mahasiswa terhadap materi.

Kepribadian adalah karakteristik unik seseorang yang mempengaruhi perilaku (Weiten W, Lloyd MA, Dunn DS, Hammer EY, 2009). Literatur lain menyebutkan definisi kepribadian adalah sesuatu yang menggambarkan karakter seseorang, bersifat stabil, dan mempengaruhi persepsi, tindakan, serta reaksi individu (Indrawati SW, 2010).

Di Fakultas Kedokteran Universitas Muhammadiyah Malang (FK UMM), belum pernah dilakukan identifikasi gaya belajar mahasiswa sehingga mahasiswa FK UMM tidak menyadari gaya belajar yang dimilikinya. Hal ini dapat menjadi salah satu faktor yang menyebabkan mahasiswa FK UMM sering mengalami kesulitan dalam menentukan strategi belajar yang tepat bagi dirinya. Di sisi lain, identifikasi kepribadian mahasiswa belum dilakukan secara rutin.

Dengan adanya pengaruh kepribadian terhadap perilaku seseorang, maka dapat diasumsikan bahwa kepribadian dapat mempengaruhi gaya belajar yang merupakan suatu bentuk gambaran sikap dan perilaku dalam belajar. Sampai saat ini belum terdapat penelitian mengenai hubungan kepribadian dan gaya belajar. Oleh karena itu penulis tertarik untuk meneliti mengenai hubungan kepribadian dan gaya belajar mahasiswa di FK UMM. Penelitian ini juga dapat membantu mahasiswa untuk mengidentifikasi kepribadian dan gaya belajar masing-masing sehingga mahasiswa 
mengetahui kepribadian dan gaya belajar mereka. Setelah mengetahui kepribadian dan gaya belajar masing-masing, mahasiswa diharapkan dapat memperbaiki kekurangan pribadi dan mengoptimalkan gaya belajar mereka. Pada akhirnya hal ini diharapkan dapat meningkatkan kualitas dan hasil belajar mahasiswa.

\section{METODE}

Penelitian ini menggunakan desain penelitian cross sectional. Populasi penelitian adalah mahasiswa FK UMM tahun angkatan 2007, 2008, 2009 dan 2010. Sampel penelitian menggunakan total sampling. Kriteria inklusi sampel adalah Mahasiswa FK UMM angkatan 2007, 2008, 2009 dan 2010 yang hadir saat penelitian serta bersedia ikut dalam penelitian. Kriteria eksklusi sampel adalah mahasiswa FK UMM tahun angkatan 2007, 2008, 2009 dan 2010 yang drop-out. Analisis data menggunakan analisis statistik chi-square dengan program SPSS 13.

\section{HASIL PENELITIAN}

Dari 510 mahasiswa, diperoleh data lengkap hanya dari 480 orang mahasiswa. Kelengkapan data yang dibutuhkan meliputi variabel utama dan variabel perancu. Variabel utama terdiri dari variabel tergantung dan variabel bebas. Berdasarkan kerangka konsep dalam penelitian ini, variabel tergantung adalah gaya belajar dan variabel bebas adalah kepribadian mahasiswa. Sedangkan variabel perancu yang diduga dapat mempengaruhi penelitian ini adalah karakteristik sosio-demografi (jenis kelamin, usia, dan asal SMU) mahasiswa. Hasil penelitian dianalisis secara univariat, bivariat dan multivariat.
Analisis Univariat terhadap berbagai variabel yang terlibat dalam penelitian

Tabel 7. Distribusi mahasiswa berdasarkan karakteristik demografi (jenis kelamin, usia, asal SMU), dan semester

\begin{tabular}{|c|c|c|c|}
\hline \multicolumn{2}{|c|}{ Karakteristik Demografi } & \multirow{2}{*}{$\frac{\mathbf{n}}{165}$} & \multirow{2}{*}{$\frac{\%}{34,4}$} \\
\hline Jenis Kelamin & Laki-laki & & \\
\hline Mahasiswa & Perempuan & 315 & 65,6 \\
\hline \multirow[t]{8}{*}{ Usia Mahasiswa } & 16 & 1 & 0,2 \\
\hline & 17 & 26 & 5,4 \\
\hline & 18 & 96 & 20 \\
\hline & 19 & 109 & 227 \\
\hline & 20 & 114 & 23,8 \\
\hline & 21 & 98 & 20,4 \\
\hline & 22 & 27 & 5,6 \\
\hline & 23 & 9 & 1,9 \\
\hline \multirow[t]{2}{*}{$\overline{\text { Asal SMU }}$} & Jawa & 385 & 80,2 \\
\hline & Luar Jawa & 95 & 19,8 \\
\hline \multirow[t]{4}{*}{ Semester } & 1 & 140 & 29,2 \\
\hline & 3 & 140 & 29,2 \\
\hline & 5 & 101 & 21 \\
\hline & 7 & 99 & 20,6 \\
\hline
\end{tabular}

Dari tabel 7 terlihat bahwa sebagian besar $(65.6 \%)$ mahasiswa adalah perempuan dan $80.2 \%$ berasal dari SMU di Jawa. Usia mahasiswa bervariasi mulai dari 16 thn sampai dengan 23 tahun. Jumlah mahasiswa terbanyak pada semester 1 dan 3 serta paling sedikit pada semester 7. Sedangkan karakteristik mahasiswa berdasarkan tipe kepribadian dapat ditunjukkan pada tabel 8 di bawah ini.

Tabel 8. Karakteristik mahasiswa berdasarkan tipe kepribadiannya

\begin{tabular}{lcc}
\hline \multicolumn{1}{c}{ Ke pribadian } & $\mathbf{n}$ & $\mathbf{\%}$ \\
\hline Abasement & 15 & 3,1 \\
Achievement & 54 & 11,3 \\
Affiliation & 7 & 1,5 \\
Agres sion & 37 & 7,7 \\
Autonomy & 18 & 3,8 \\
Change & 30 & 6,3 \\
Defference & 6 & 1,3 \\
Dominance & 64 & 13,3 \\
Endurance & 20 & 4,2 \\
Exhibition & 68 & 14,2 \\
Heterosexuality & 16 & 3,3 \\
Intraception & 63 & 13,1 \\
Nurturance & 30 & 6,3 \\
Order & 12 & 2,5 \\
Succorance & 40 & 8,3 \\
\hline
\end{tabular}

Tabel 8 menunjukkan bahwa sebagian besar (14.2 \%) mahasiswa memiliki tipe kepribadian Exhibition diikuti dengan tipe kepribadian Dominance (13.3 
\%), Intraseption (13.1\%), Achievement (11.3\%), Succorance $(8.3 \%)$ dan seterusnya sampai yang paling sedikit jumlahnya adalah Defference (1.3 $\%)$.

Tabel 9. Distribusi mahasiswa berdasarkan gaya belajar

\begin{tabular}{llcc}
\hline \multicolumn{2}{c}{ Variabel } & N & \% \\
\hline Gaya Belajar & Activist & 103 & 21,5 \\
& Pragmatist & 65 & 13,5 \\
& Reflector & 278 & 57,9 \\
& Theorist & 34 & 7,1 \\
\hline
\end{tabular}

Dari 480 mahasiswa, sebagian besar mahasiswa memiliki gaya belajar Reflector $(57.9 \%)$.

Analisis Bivariat berbagai variabel terhadap gaya belajar

Tabel 10. Hubungan antara kepribadian dengan gaya belajar

\begin{tabular}{|c|c|c|c|c|c|c|}
\hline & \multirow{2}{*}{ Variabel } & \multicolumn{4}{|c|}{ Gaya Belajar } & \multirow[b]{2}{*}{$\mathbf{P}$} \\
\hline & & Activist & Pragmatist & Reflector & Teorist & \\
\hline \multirow{15}{*}{$\begin{array}{l}\mathbf{K} \\
\mathbf{E} \\
\mathbf{P} \\
\mathbf{R} \\
\mathbf{I} \\
\mathbf{B} \\
\mathbf{A} \\
\mathbf{D} \\
\mathbf{I} \\
\mathbf{A} \\
\mathbf{N}\end{array}$} & Abasement & $\begin{array}{c}0 \\
0 \%\end{array}$ & $\begin{array}{c}4 \\
(26.7 \%) \\
\end{array}$ & $\begin{array}{c}9 \\
(60.0 \%) \\
\end{array}$ & $\begin{array}{c}2 \\
(13.3 \%) \\
\end{array}$ & \multirow{15}{*}{0,693} \\
\hline & Achievement & $\begin{array}{c}12 \\
(222 \%) \\
\end{array}$ & $\begin{array}{c}9 \\
(16.7 \%) \\
\end{array}$ & $\begin{array}{c}27 \\
(50.0 \%) \\
\end{array}$ & $\begin{array}{c}6 \\
(111 \%) \\
\end{array}$ & \\
\hline & Affiliation & $\begin{array}{c}1 \\
(14.3 \%) \\
\end{array}$ & $\begin{array}{c}2 \\
(28.6 \%) \\
\end{array}$ & $\begin{array}{c}4 \\
(57.1 \%) \\
\end{array}$ & $\begin{array}{c}0 \\
(.0 \%) \\
\end{array}$ & \\
\hline & Agression & $\begin{array}{c}7 \\
(18.9 \%) \\
\end{array}$ & $\begin{array}{c}8 \\
(21.6 \%) \\
\end{array}$ & $\begin{array}{c}20 \\
(54.1 \%) \\
\end{array}$ & $\begin{array}{c}2 \\
(5.4 \%) \\
\end{array}$ & \\
\hline & Autonomy & $\begin{array}{c}4 \\
\left(22.2^{\circ} \%\right)\end{array}$ & $\begin{array}{c}4 \\
(22.2 \%)\end{array}$ & $\begin{array}{c}9 \\
(50.0 \%)\end{array}$ & $\begin{array}{c}1 \\
(5.6 \%)\end{array}$ & \\
\hline & Change & $\begin{array}{c}6 \\
(20.0 \%) \\
\end{array}$ & $\begin{array}{c}5 \\
(16.7 \%) \\
\end{array}$ & $\begin{array}{c}16 \\
(53.3 \%) \\
\end{array}$ & $\begin{array}{c}3 \\
(10.0 \%) \\
\end{array}$ & \\
\hline & Difference & $\begin{array}{c}0 \\
(.0 \%) \\
\end{array}$ & $\begin{array}{c}0 \\
(.0 \%) \\
\end{array}$ & $\begin{array}{c}5 \\
(83.3 \%) \\
\end{array}$ & $\begin{array}{c}1 \\
(16.7 \%) \\
\end{array}$ & \\
\hline & Dominance & $\begin{array}{c}16 \\
(25.0 \%) \\
\end{array}$ & $\begin{array}{c}5 \\
(7.8 \%) \\
\end{array}$ & $\begin{array}{c}37 \\
(57.8 \%)\end{array}$ & $\begin{array}{c}6 \\
(9.4 \%)\end{array}$ & \\
\hline & Endurance & $\begin{array}{c}3 \\
(15.0 \%) \\
\end{array}$ & $\begin{array}{c}2 \\
(10.0 \%) \\
\end{array}$ & $\begin{array}{c}15 \\
(75.0 \%) \\
\end{array}$ & $\begin{array}{c}0 \\
(.0 \%) \\
\end{array}$ & \\
\hline & Exhibition & $\begin{array}{c}18 \\
(26.5 \%) \\
\end{array}$ & $\begin{array}{c}9 \\
(13.2 \%) \\
\end{array}$ & $\begin{array}{c}35 \\
(51.5 \%) \\
\end{array}$ & $\begin{array}{c}6 \\
(8.8 \%) \\
\end{array}$ & \\
\hline & Heterosex uality & $\begin{array}{c}5 \\
(31.3 \%) \\
\end{array}$ & $\begin{array}{c}3 \\
(18.8 \%) \\
\end{array}$ & $\begin{array}{c}7 \\
(43.8 \%) \\
\end{array}$ & $1(6.3 \%)$ & \\
\hline & Intraseption & $\begin{array}{c}12 \\
(19.0 \%) \\
\end{array}$ & $\begin{array}{c}4 \\
(6.3 \%) \\
\end{array}$ & $\begin{array}{c}45 \\
(71.4 \%) \\
\end{array}$ & $\begin{array}{c}2 \\
(3.2 \%) \\
\end{array}$ & \\
\hline & Nurturance & $\begin{array}{c}7 \\
(23.3 \%)\end{array}$ & $\begin{array}{c}5 \\
(16.7 \%)\end{array}$ & $\begin{array}{c}17 \\
(56.7 \%)\end{array}$ & $\begin{array}{c}1 \\
(3.3 \%)\end{array}$ & \\
\hline & Order & $\begin{array}{c}2 \\
(16.7 \%) \\
\end{array}$ & $\begin{array}{c}1 \\
(8.3 \%) \\
\end{array}$ & $\begin{array}{c}7 \\
(58.3 \%) \\
\end{array}$ & $\begin{array}{c}2 \\
(16.7 \%) \\
\end{array}$ & \\
\hline & Succhorance & $\begin{array}{c}10 \\
(25.0 \%) \\
\end{array}$ & $\begin{array}{c}4 \\
(10.0 \%) \\
\end{array}$ & $\begin{array}{c}25 \\
(62.5 \%)\end{array}$ & $\begin{array}{c}1 \\
(2.5 \%) \\
\end{array}$ & \\
\hline
\end{tabular}


Tabel 11. Hubungan antara karakteristik sosio-demografi mahasiswa dengan gaya belajar

\begin{tabular}{|c|c|c|c|c|c|c|}
\hline \multirow{2}{*}{\multicolumn{2}{|c|}{ Variabel }} & \multicolumn{4}{|c|}{ Gaya Belajar } & \multirow[b]{2}{*}{$\mathbf{P}$} \\
\hline & & Activist & Pragmatist & Reflector & Teorist & \\
\hline \multirow{9}{*}{$\begin{array}{l}\text { Usia } \\
\text { Mahasiswa }\end{array}$} & 16 & $\begin{array}{c}0 \\
0 \% \\
\end{array}$ & $\begin{array}{c}0 \\
0 \% \\
\end{array}$ & $\begin{array}{c}1 \\
(100.0 \%) \\
\end{array}$ & $\begin{array}{c}0 \\
0 \% \\
\end{array}$ & \multirow{9}{*}{0.244} \\
\hline & 17 & $\begin{array}{c}6 \\
(23.1 \%) \\
\end{array}$ & $\begin{array}{c}2 \\
(7.7 \%) \\
\end{array}$ & $\begin{array}{c}17 \\
(65.4 \%) \\
\end{array}$ & $\begin{array}{c}1 \\
(3.8 \%) \\
\end{array}$ & \\
\hline & 18 & $\begin{array}{c}24 \\
\left(25.0^{\circ} \%\right) \\
\end{array}$ & $\begin{array}{c}9 \\
(9.4 \%) \\
\end{array}$ & $\begin{array}{c}60 \\
(62.5 \%) \\
\end{array}$ & $\begin{array}{c}3 \\
(3.1 \%) \\
\end{array}$ & \\
\hline & 19 & $\begin{array}{c}21 \\
(19.3 \%) \\
\end{array}$ & $\begin{array}{c}16 \\
14.7 \% \\
\end{array}$ & $\begin{array}{c}62 \\
56.9 \% \\
\end{array}$ & $\begin{array}{c}10 \\
9.2 \% \\
\end{array}$ & \\
\hline & & 16 & 16 & 74 & 8 & \\
\hline & 20 & $(14.0 \%)$ & $(14.0 \%)$ & $(64.9 \%)$ & $(7.0 \%)$ & \\
\hline & 21 & $\begin{array}{c}26 \\
(26.5 \%) \\
\end{array}$ & $\begin{array}{c}16 \\
(16.3 \%) \\
\end{array}$ & $\begin{array}{c}49 \\
(50.0 \%) \\
\end{array}$ & $\begin{array}{c}7 \\
(7.1 \%) \\
\end{array}$ & \\
\hline & 22 & $\begin{array}{c}6 \\
(22.2 \%) \\
\end{array}$ & $\begin{array}{c}3 \\
(11.1 \%) \\
\end{array}$ & $\begin{array}{c}14 \\
(51.9 \%) \\
\end{array}$ & $\begin{array}{c}4 \\
(14.8 \%) \\
\end{array}$ & \\
\hline & 23 & $\begin{array}{c}4 \\
(44.4 \%)\end{array}$ & $\begin{array}{c}3 \\
(33.3 \%)\end{array}$ & $\begin{array}{c}1 \\
(11.1 \%)\end{array}$ & $\begin{array}{c}1 \\
(11.1 \%)\end{array}$ & \\
\hline \multirow{2}{*}{$\begin{array}{l}\text { Jenis Kelamin } \\
\text { Mahasiswa }\end{array}$} & $\begin{array}{l}\text { Perempua } \\
n\end{array}$ & $\begin{array}{c}64 \\
(20.3 \%) \\
\end{array}$ & $\begin{array}{c}33 \\
(10.5 \%) \\
\end{array}$ & $\begin{array}{c}192 \\
(61.0 \%) \\
\end{array}$ & $\begin{array}{c}26 \\
(8.3 \%) \\
\end{array}$ & \multirow{2}{*}{0.017} \\
\hline & Laki-laki & $\begin{array}{c}39 \\
(23.6 \%) \\
\end{array}$ & $\begin{array}{c}32 \\
(19.4 \%) \\
\end{array}$ & $\begin{array}{c}86 \\
(52.1 \%) \\
\end{array}$ & $\begin{array}{c}8 \\
(4.8 \%) \\
\end{array}$ & \\
\hline \multirow{2}{*}{$\begin{array}{l}\text { Asal SMU } \\
\text { Mahasiswa }\end{array}$} & Luar Jawa & $\begin{array}{c}19 \\
(20.0 \%) \\
\end{array}$ & $\begin{array}{c}7 \\
(7.4 \%) \\
\end{array}$ & $\begin{array}{c}65 \\
(68.4 \%) \\
\end{array}$ & $\begin{array}{c}4 \\
\left(4.2^{\circ} \%\right) \\
\end{array}$ & \multirow{2}{*}{$0.06 \mathrm{C}$} \\
\hline & Jawa & $\begin{array}{c}84 \\
(21.8 \%) \\
\end{array}$ & $\begin{array}{c}58 \\
(15.1 \%) \\
\end{array}$ & $\begin{array}{c}213 \\
(55.3 \%) \\
\end{array}$ & $\begin{array}{c}30 \\
(7.8 \%) \\
\end{array}$ & \\
\hline \multirow{4}{*}{ Semester } & 1 & $\begin{array}{c}31 \\
(22.1 \%) \\
\end{array}$ & $\begin{array}{c}14 \\
(10.0 \%) \\
\end{array}$ & $\begin{array}{c}91 \\
(65.0 \%) \\
\end{array}$ & $\begin{array}{c}4 \\
(2.9 \%) \\
\end{array}$ & \multirow{4}{*}{0.009} \\
\hline & 3 & $\begin{array}{c}31 \\
(22.1 \%) \\
\end{array}$ & $\begin{array}{c}23 \\
(16.4 \%) \\
\end{array}$ & $\begin{array}{c}73 \\
(52.1 \%) \\
\end{array}$ & $\begin{array}{c}13 \\
(9.3 \%) \\
\end{array}$ & \\
\hline & 5 & $\begin{array}{c}11 \\
(10.9 \%) \\
\end{array}$ & $\begin{array}{c}14 \\
(13.9 \%)\end{array}$ & $\begin{array}{c}68 \\
(67.3 \%) \\
\end{array}$ & $\begin{array}{c}8 \\
(7.9 \%)\end{array}$ & \\
\hline & 7 & $\begin{array}{c}30 \\
(30.3 \%) \\
\end{array}$ & $\begin{array}{c}14 \\
(14.1 \%) \\
\end{array}$ & $\begin{array}{c}46 \\
(46.5 \%) \\
\end{array}$ & $\begin{array}{c}9 \\
(9.1 \%) \\
\end{array}$ & \\
\hline
\end{tabular}

\section{DISKUSI}

\section{Hubungan Kepribadian Mahasiswa dengan Gaya belajar}

Hasil tes kepribadian terhadap 480 mahasiswa FK UMM menunjukkan sebagian besar mahasiswa memiliki tipe kepribadian Exhibition yaitu kebutuhan untuk menonjolkan diri. Tipe kepribadian ini menunjang pembelajaran di FK UMM yang menuntut mahasiswa untuk aktif berdiskusi dalam tutorial, aktif menyampaikan pendapat ataupun informasi, aktif bertanya dan mampu menunjukkan ketrampilan klinis yang dikuasai dalam pembelajaran ketrampilan klinik dasar (skills lab). Tipe kepribadian ini juga menunjang kemampuan mahasiswa untuk berpikir kritis dengan cara mengevaluasi informasi secara kritis melalui komentar, pertanyaan atau pendapat yang disampaikan. Selain itu tipe kepribadian ini dapat menunjang motivasi mahasiswa untuk belajar lebih baik dan meningkatkan prestasi belajar. Data kepribadian yang ada dapat digunakan untuk bahan bimbingan mahasiswa atau konseling.

Namun dari lima belas tipe kepribadian, tidak terdapat hubungan antara kepribadian mahasiswa dengan gaya belajar $(p>0,05)$. Hal ini dapat dimungkinkan karena gaya belajar merupakan hasil reaksi terhadap lingkungan belajar (Madyana AM, 2008). Faktor internal mahasiswa yang mempengaruhi gaya belajar adalah umur dan jenis kelamin (Curry L, 2002).

Gaya belajar sebagian besar mahasiswa di FK UMM adalah Reflector (57.9\%), diikuti dengan Activist, Pragmatist dan Theorist. Hal ini mungkin berhubungan dengan jenis kelamin perempuan yang 
mendominasi populasi penelitian (65.6 \%). Kenyataan ini sesuai dengan hasil penelitian gaya belajar di mahasiswa keperawatan UGM. Dalam penelitian tersebut dikatakan bahwa hasil penelitian ini sesuai dengan pendapat Honey dan Mumford bahwa perempuan cenderung memiliki gaya belajar reflector dan theorist karena perempuan cenderung menggunakan otak kirinya. Proses berpikir otak kiri bersifat logis, sekuensial, linier dan rasional. Cara berpikir demikian sesuai untuk tugas-tugas teratur, ekspresi verbal, menulis, membaca, asosiasi auditorial, serta menempatkan detail dan fakta. ${ }^{50}$

Data gaya belajar tersebut dapat membantu mahasiswa untuk mengidentifikasi gaya belajar mereka masing-masing sehingga mereka dapat mengoptimalkan belajar mereka. Hasil gambaran gaya belajar mahasiswa ini memberikan masukan bagi pihak staf pengajar untuk mengadakan kegiatan pembelajaran yang dapat mengakomodir semua gaya belajar tersebut. Berikut ini contoh dari konsep kegiatan pembelajaran yang dapat mengakomodir semua gaya belajar.

Konsep kegiatan belajar mengajar dengan mengakomodir gaya belajar.

$\begin{array}{ll}\text { Mata Kuliah } & \text { : Ilmu Kedokteran Komunitas } \\ \text { Topik } & \text { : Sistem pelayanan kesehatan }\end{array}$

Strategi pembelajaran :

a. kuliah

b. tugas lapangan ke tempat pelayanan kesehatan secara berkelompok

c. hasil tugas lapangan dibuat makalah (disertai dengan literatur reading) dan dipresentasikan

d. diskusi kelompok4 8

Strategi pembelajaran kuliah dapat mengakomodir gaya belajar theorist. Sedangkan tugas lapangan ke tempat pelayanan kesehatan dapat mendukung pembelajaran gaya belajar activist dan pragmatis. Tugas kelompok dapat mendukung gaya belajar pragmatis. Tugas pembuatan makalah hasil tugas lapangan yang melibatkan kegiatan membaca literatur sebagai tinjauan pustaka merupakan strategi untuk mengakomodir gaya belajar reflector. Selain itu pada saat pembuatan tugas tersebut juga melibatkan review analitik terhadap kenyataan di tempat pelayanan kesehatan. Hal ini mendukung gaya belajar theorist. Presentasi hasil tugas lapangan di depan kelas dapat mengakomodir gaya belajar activist. Sedangkan diskusi kelompok saat pembuatan tugas dan presentasi dapat mengakomodir gaya belajar activist dan pragmatis.

Namun demikian, perlu disadari semua pihak bahwa KBK dengan pendekatan PBL membutuhkan keempat gaya belajar tersebut yang terangkum dalam suatu siklus belajar efektif. Jadi tidak diharapkan untuk belajar dengan mengandalkan hanya salah satu gaya belajar saja. Masing-masing gaya belajar tersebut memiliki kekuatan dan kelemahan. Hal tersebut tidak membuat salah satu gaya belajar lebih superior dari yang lain. Dengan kekuatan dan kelemahan yang dimiliki maka kita dapat mengetahui kapan saat yang tepat untuk penerapan masing-masing gaya belajar. Selain itu dengan mengetahui kekuatan dan kelemahan masing-masing gaya belajar maka kita dapat mengoptimalkan kekuatan tersebut dan memperbaiki kelemahannya pada situasi yang diperlukan. $^{24}$

Bila dilihat dari jumlah penggabungan, gaya belajar Reflector-Theorist yang merupakan bagian penelaahan dan berpikir dari siklus belajar, merupakan gaya belajar yang dominan dibandingkan dengan gaya belajar Activist-Pragmatist yang merupakan bagian tindakan dan perencanaan. Hal ini kemungkinan dapat disebabkan karena metode pembelajaran kuliah di FK UMM masih lebih banyak proporsinya dibandingkan dengan metode experiential learning yang dapat meningkatkan kecenderungan gaya belajar Activist-Pragmatist. ${ }^{51}$

\section{Hubungan Karakteristik Sosio-Demografi Mahasiswa dengan Gaya Belajar}

Karakteristik sosio-demografi mahasiswa yang diukur dalam penelitian ini adalah jenis kelamin, usia, asal SMU dan semester. Dari hasil uji statistik menunjukkan bahwa jenis kelamin dan semester memiliki hubungan yang signifikan dengan gaya belajar mahasiswa. Hal ini sesuai dengan literatur yang menyatakan bahwa gaya belajar dipengaruhi oleh umur, jenis kelamin dan variasi budaya (Curry L, 2002). Hubungan yang signifikan antara semester dengan gaya belajar mahasiswa memiliki arti bahwa mahasiswa yang berada di semester lebih tinggi dan usianya lebih tua, memiliki lebih banyak pengalaman dan pengetahuan dibanding mahasiswa yang berada di semester lebih rendah dan usianya lebih muda. Dengan banyaknya pengalaman dan pengetahuan yang dimiliki, dapat dimungkinkan mahasiswa yang berada di semester lebih tinggi 
dan usianya lebih tua akan lebih mudah menyesuaikan gaya belajar mereka dengan lingkungan belajarnya.

Di sisi lain usia dan asal SMU tidak berhubungan dengan gaya belajar. Hal ini bertentangan dengan literatur yang menyatakan bahwa gaya belajar dipengaruhi oleh umur, dan variasi budaya (Curry L, 2002). Kenyataan ini juga tidak sesuai dengan hasil penelitian yang menunjukkan adanya hubungan antara semester dengan gaya belajar karena seharusnya usia dan semester saling berkaitan dalam arti semakin tinggi semester semakin tua usia mahasiswanya. Tidak adanya hubungan antara asal SMU dengan gaya belajar dapat disebabkan karena asal SMU kurang menunjukkan latar belakang budaya mahasiswa. Variasi budaya mungkin dapat lebih ditunjukkan oleh data suku bangsa atau asal tempat tinggal.

\section{Implikasi Penelitian}

Penelitian ini memberikan implikasi bahwa kegiatan pembelajaran perlu mengakomodir gaya belajar mahasiswa. Selain itu, perlu adanya identifikasi dan pengenalan gaya belajar mahasiswa sejak semester 1 agar dapat membantu mahasiswa mengoptimalkan strategi dan hasil belajarnya. Pengenalan konsep dan pentingnya kesadaran mengenai gaya belajar sebagai bagian dari strategi belajar yang efektif dan efisien kepada mahasiwa perlu dilakukan sejak semester 1 karena sesuai dengan tahap pendidikan kedokteran mahasiswa yaitu tahap general education. Secara keseluruhan hasil penelitian ini diharapkan dapat membantu perbaikan dan pengembangan implementasi KBK dengan pendekatan PBL khususnya di FK UMM dan umumnya di FK lainnya.

\section{Keterbatasan Penelitian}

Keterbatasan penelitian ini terletak pada tes kepribadian yang diteliti. Penelitian berikutnya dapat meneliti hubungan kepribadian dengan gaya belajar menggunakan tipe-tipe kepribadian yang lain. Keterbatasan waktu juga menjadi faktor yang dapat diperbaiki dalam penelitian lebih lanjut. Keterbatasan lain adalah mengenai faktor variasi budaya yang diteliti hanya sebatas pada informasi asal SMU sehingga perlu diteliti lebih lanjut faktor variasi budaya dari suku bangsa atau asal tempat tinggal.
Keterbatasan penelitian ini juga meliputi belum adanya identifikasi dan analisis multivariat secara bersamaan dari faktor internal dan eksternal yang mempengaruhi gaya belajar mahasiswa. Penelitian ini hanya meneliti sebagian saja dari faktor internal dan eksternal mahasiswa yang dapat mempengaruhi gaya belajar sehingga hasilnya mungkin dapat berbeda bila dibandingkan dengan hasil analisis multivariat faktor internal dan eksternal mahasiswa (dilakukan secara bersamaan) terhadap gaya belajar. Hal ini dapat menjadi usulan penelitian selanjutnya.

\section{SIMPULAN}

Dari hasil penelitian mengenai hubungan antara kepribadian mahasiswa dengan gaya belajar didapatkan simpulan yaitu kepribadian mahasiswa tidak berhubungan dengan gaya belajar mahasiswa. Karakteristik sosiodemografi mahasiswa yang berhubungan dengan gaya belajar mahasiswa adalah jenis kelamin dan semester sedangkan usia dan asal SMU tidak berhubungan dengan gaya belajar.

\section{SARAN}

Perlu penelitian lebih lanjut mengenai pengaruh faktor internal mahasiswa dan eksternal secara bersamaan dalam suatu analisis multivariat terhadap gaya belajar mahasiswa agar dapat menguatkan kerangka teori. Penelitian selanjutnya dapat diadakan dalam waktu yang lebih lama dan bersifat prospektif dengan tes kepribadian tipe lain. Penelitian selanjutnya juga dapat meneliti pengaruh asal suku bangsa dan asal tempat tinggal terhadap gaya belajar mahasiswa sehingga hasil penelitian mengenai pengaruh budaya terhadap gaya belajar mahasiswa dapat lebih spesifik. 


\section{DAFTAR PUSTAKA}

Anastasi A, Urbina S. Tes Psikologi. Edisi Bahasa Indonesia dari Psychological Testing, $7^{\text {th }}$ ed. 1998. Jakarta : Prenhallindo

Coffield F, Moseley D, Hall E \& Ecclestone K. Learning styles and pedagogy in post-16 learning:a systematic and critical review. The Learning and Skills Research Centre Reference. Wiltshire:Cromwell Press Ltd;2004

Curry L. Individual Differences in Cognitive Style, Learning Style and Instructional Preference in Medical Education. Dalam : International Handbook of Research in Medical Education. Editor : Norman, Van der Veuten, Newble. Belanda. Kluwer Academic Publishers. 2002

Duff A, Duffy T. Psychometric properties of Honey \& Mumford's Learning Styles Questionnaire (LSQ). Personality and Individual Differences. 2002; 33:147-163. www.elsevier.com/locate/paid

Grace M. Learning styles. British Dental Journal. 2001; 191(3):125-8

Indrawati SW. Tes Psikologis (Tes EPPS). Jurusan psikologi pendidikan dan bimbingan FIP UPI. Bandung. http://file.upi.edu/ ai.php?dir=Direktori / A - FI P / JUR.PSIKOLOGI/195010101980022. Diunduh pada tanggal 26 Mei 2010

Lockitt B. Learning styles:into the future. Dorset:Blackmore Limited;1997

Madyana AM. Pengaruh faktor gaya belajar terhadap prestasi mahasiswa FTP UGM. 1994. Dalam : Suryawantie T, Rahayu GR, Prabowo T. Gaya belajar mahasiswa program studi ilmu keperawatan Fakultas Kedokteran Universitas Gadjah Mada Yogyakarta. Jurnal Pendidikan Kedokteran dan Profesi Kesehatan Indonesia. 2008;3(1):27-35

Pamungkas Y. Manual EPPS edisi bahasa Indonesia. 2005. Malang : Laboratorium Psikologi Universitas Muhammadiyah Malang

Sadock BJ, Sadock VA. Synopsis of Psychiatry, Behavioral Sciences/Clinical Psychiatry. $9^{\text {th }}$ ed. 2003. Philadelphia USA : Lippincott Williams \& Wilkins
Sukardi DK. Analisisi inventori minat dan kepribadian. 1993. Jakarta : Rineka Cipta

Weiten W, Lloyd MA, Dunn DS, Hammer EY. Theories of Personality in : Psychology Applied to Modern Life, Adjustment in the $21^{\text {st }}$ century. 2009. Wadsworth Cengage Learning. USA. p:32-69 
